\title{
Biblioterapia: estudo comparativo das práticas biblioterápicas brasileiras e norte- americanas
}

\author{
Bibliotherapy: comparative study on bibliotherapeutic practices in Brazil \\ and in United States
}

\section{La biblioterapia: un estudio comparativo de las prácticas biblioterapéuticas del Brasil y de Estados Unidos}

\author{
Andréa Pereira dos Santos | andreabiblio@gmail.com \\ Universidade Federal de Goiás, Goiânia, Goiás, Brasil \\ Rubem Borges Teixeira Ramos | rubem ramos@hotmail.com \\ Universidade Federal de Goiás, Goiânia, Goiás, Brasil \\ Thais Caroline Silva Sousa | thaiscaroline.sousa@hotmail.com \\ Universidade Federal de Goiás, Goiânia, Goiás, Brasil
}

\section{Resumo}

A biblioterapia é um processo de leitura que auxilia as pessoas a controlarem seus sentimentos e assim buscarem estratégias para resolver seus problemas tanto de ordem psicológica quanto física. A partir dessa afirmação e sabendo da necessidade de aprofundamento nessa área, apresentamos uma revisão de literatura sobre o tema no contexto nacional e norte-americano. Buscamos apresentar uma breve descrição do processo de leitura, em especial da leitura terapêutica e de sua aplicação nas práticas biblioterapêuticas. No Brasil, os projetos de biblioterapia revelaram práticas voltadas para a leitura de livros, música, desenhos e outros instrumentos em escolas, asilos, hospitais, etc. Os norte-americanos utilizaram como instrumento em seus projetos fundamentalmente a leitura de livros. Percebe-se que a biblioterapia possui resultados positivos nos dois países. Concluímos que a prática da biblioterapia contribui para melhorar a qualidade de vida.

Palavras-chave: biblioterapia; leitura terapêutica; projetos de biblioterapia; biblioterapia brasileira e norte-americana; revisão de literatura. 


\begin{abstract}
Bibliotherapy is a reading process, which helps people to control their feelings so that they can seek strategies to solve their psychological and physical problems. From this statement, and knowing the benefits this area would achieve by going further on research, a review of the literature in bibliotherapy was made, focusing on Brazil and United States. We attempted to provide a short description of the process of reading, particularly the therapeutic reading and its use in bibliotherapeutic practices. In Brazil, the projects in the field of bibliotherapy demonstrated activities using books, music, drawings and other instruments in schools, nursing homes, hospitals, and so on... North Americans, on the other hand, fundamentally used the books as tool on their projects. It is possible to note that bibliotherapy has positive results in both countries. We have come to the conclusion that the bibliotherapy contributes to improve the quality of life.
\end{abstract}

Keywords: bibliotherapy; therapeutic reading; bibliotherapy projects; Brazilian and American bibliotherapy; literature review.

\title{
Resumen
}

La biblioterapia es un proceso de lectura que ayuda a las personas a controlar sus sentimientos y así buscar estrategias que puedan resolver sus problemas tanto psicológicos como físicos. A partir de esta declaración y conociendo la necesidad de un mayor desarrollo en este campo de actividad, presentamos una revisión literaria sobre el tema de la biblioterapia en el contexto de Brasil y de Estados Unidos. Se buscó presentar una breve descripción del proceso de la lectura, especialmente la lectura terapéutica y su aplicación en las prácticas biblioterapéuticas. En Brasil, los proyectos de biblioterapia presentaron prácticas destinadas a la lectura de libros, música, dibujos y otros instrumentos en las escuelas, asilos, hospitales, etc. Los norteamericanos utilizaron fundamentalmente la lectura de libros como una herramienta en sus proyectos. Se observa que la biblioterapia tiene resultados positivos en ambos países. Concluimos que la práctica de biblioterapia ayuda a mejorar la calidad de vida.

Palabras clave: biblioterapia; lectura terapéutica; proyectos de biblioterapia; biblioterapia brasileña y norteamericana; revisión literaria .

Contribuição dos autores: os autores declaram ter contribuído em todas as fases de produção do texto

Concepção e desenho do estudo: Trata-se de uma revisão de literatura acerca das práticas biblioterápicas no Brasil e no exterior a partir de um estudo comparativo

Aquisição, análise ou interpretação dos dados : Dados adquiridos por meio de pesquisa bibliográfica e documental

Declaração de conflito de interesses: Não há.

Fontes de financiamento: Não houve.

Considerações éticas: Não há.

Agradecimento/Contribuições adicionais: Não há.

Histórico do artigo: Submetido: 19 jan 2016 | Aceito: 29 set. 2016 | Publicado: 30.jun.2016

Licença CC BY-NC atribuição não comercial. Com essa licença é permitido acessar, baixar (download), copiar, imprimir, compartilhar, reutilizar e distribuir os artigos, desde que para uso não comercial e com a citação da fonte, conferindo os devidos créditos de autoria e menção à Reciis. Nesses casos, nenhuma permissão é necessária por parte dos autores ou dos editores. 


\section{Introdução}

Biblioterapia é um tipo de terapia realizada por meio da leitura de livros e outros materiais afins em diferentes suportes. As pessoas com problemas ou doenças emocionais e/ou físicas constituem seu públicoalvo. A biblioterapia as estimula na resolução de seus problemas e a controlar suas emoções para que possam conviver socialmente e consigo mesmo.

A motivação para essa pesquisa se deu, principalmente, porque na sociedade atual, são comuns problemas emocionais; e isto pode ocorrer devido a diversos fatores, tais como estresse devido à rotina diária, traumas, depressão, entre outros: "a desestabilização de um sistema produz desequilíbrio em outros" ${ }^{\prime \prime}$. Dessa forma, é possível compreender que o estresse, depressão e outros problemas emocionais desestabilizam o equilíbrio do indivíduo. No dia o9 de outubro de 2012, véspera do Dia Mundial da Saúde Mental, a Organização Mundial da Saúde (OMS) alertou que existem mais de 350 milhões de pessoas que sofrem com a depressão. Na vida moderna, as pessoas não sabem como relaxar, pois essa realidade e o excesso de informações trazem complicações a crianças, adolescentes, adultos e idosos. Outra forma que atrai esses males emocionais são as doenças físicas, como o câncer ou dores crônicas, que atingem, por ano, milhares de pessoas ao redor do mundo. Esse tipo de doença desestabiliza as pessoas e as tornam susceptíveis aos problemas emocionais citados².

Uma forma de auxiliar o combate a essas patologias é por meio da biblioterapia, que pode ser implementada por psicólogos e/ou bibliotecários. Pode-se aplicar a biblioterapia como uma dinâmica que propicie a sociabilização, o conforto e a ajuda necessária para a resolução de problemas, perpassando também a aceitação da situação em que o leitor se encontra. Nesse caso, a biblioterapia pode ser utilizada em vários segmentos e locais, tais como asilos, orfanatos, hospitais, clínicas psiquiátricas, presídios, entre outros. A biblioterapia não é restrita a uma idade específica, sendo, portanto, aplicável a crianças, jovens, adultos e idosos ${ }^{3-4}$.

Este artigo objetiva, de forma geral, apresentar projetos e pesquisas sobre a temática biblioterapia, no contexto brasileiro e norte-americano, visando à comparação de aspectos relacionados à teoria, à prática e aos conceitos do processo terapêutico. Além de compreender as fases de planejamento da biblioterapia, escolheu-se realizar essa análise comparativa, uma vez que os estudos brasileiros existem em número reduzido, concentrando-se, na sua maioria, na Região Sul. Diante disso, sentiu-se a necessidade de conhecer projetos realizados fora do Brasil, para saber quais as diferenças relativas tanto aos conceitos quanto à aplicação da biblioterapia.

O artigo está dividido da seguinte forma: primeiramente, há uma breve descrição da leitura e da leitura terapêutica; depois, apresenta-se uma revisão de literatura da biblioterapia, introduzindo conceitos e história, mostrando critérios para a sua elaboração e aplicação. Por fim, demonstra projetos de biblioterapia nos âmbitos do Brasil e dos Estados Unidos e faz uma análise comparativa entre os dois países.

\section{Metodologia}

A pesquisa científica é uma forma de investigação de problemas teóricos ou práticos, precedidos pelo surgimento de dúvidas ou problemas; com a participação do método científico, buscam-se respostas ou soluções para esses. No presente estudo foi utilizada a pesquisa bibliográfica, pois o foco do trabalho é apresentar uma revisão de literatura referente ao conceito de biblioterapia e aos projetos realizados no Brasil e nos Estados Unidos.

"É perceptível que a pesquisa bibliográfica não costuma oferecer dados inéditos, como a pesquisa de campo ou de laboratório”. Dessa forma, revisão de literatura ou pesquisa bibliográfica consiste em uma 
busca realizada em artigos, teses, livros e dissertações sobre determinado tema. A revisão é o elemento básico para se iniciar os estudos científicos, trabalhos de conclusão de curso e monografias.

Com a revisão de literatura, é possível explorar trabalhos já realizados por diversos estudiosos e adquirir vasto conhecimento referente ao assunto pesquisado. Assim, é possível ter-se uma noção de temas ainda não abordados e, com isso, criar a possibilidade de um novo campo de pesquisa.

Trata-se, também, de uma pesquisa exploratória e qualitativa. Para isso, foram realizadas pesquisas bibliográficas nas seguintes bases de dados brasileiras: Portal de periódicos da Capes, em especial a busca de estudos internacionais; SciELO; DOAJ; Google Acadêmico e Biblioteca Digital de Teses e Dissertações do Ibict. As palavras-chave utilizadas em língua portuguesa foram: biblioterapia; leitura terapêutica; leitura e terapia. Já em língua estrangeira, optou-se por: bibliotherapy, read and therapy. A preferência foi dada a artigos, dissertações e teses sem data específica de início, porém finalizados até 2012.

Foram encontrados 18 iniciativas brasileiras entre 1982 e 2012. Já entre as publicações norte-americanas, foram encontradas sete, entre os anos de 1949 e 2012. É interessante lembrar que a opção aqui escolhida foi por concentrar a busca internacional somente nos Estados Unidos, o que demonstra uma menor quantidade de artigos em comparação aos estudos brasileiros, embora a população norte-americana, à época da pesquisa, já contasse com uma população de mais de 300 milhões de cidadãos, quase o dobro da população brasileira.

\section{Leitura como terapia}

Para se entender a biblioterapia, cabe conhecer o conceito a que se refere a leitura e a realização dessa prática entre as pessoas. "O conceito de leitura está geralmente restrito à decifração da escrita, sua aprendizagem. No entanto, liga-se por tradição ao processo de formação global do individuo, à sua capacitação para o convívio e às atuações social, política, econômica e cultural”.6.

A leitura está presente no contexto terapêutico. "A função terapêutica da leitura admite a possibilidade de a literatura proporcionar a pacificação das emoções" ". A leitura de histórias propicia ao leitor extrair emoções reprimidas e incentiva a resolução de problemas. A leitura de textos literários é capaz de ser curativa e alterar o estado psíquico do leitor, amenizando os sofrimentos e transtornos. Essa leitura terapêutica é chamada de biblioterapia.

Apontam-se as diversas formas da leitura como função terapêutica utilizadas antigamente. No antigo Egito, o Faraó Rammsés II, colocou no frontispício de sua biblioteca a frase "Remédios para a alma”3 , e as bibliotecas se localizavam em templos denominados "casas da vida"8. O romano Aulus Cornelius Celsus utilizou a leitura como procedimento médico, recomendando-a assim como a discussão de obras de grandes estudiosos da época para gerar o lado crítico de seus pacientes. A biblioteca da Abadia de São Gall tinha exposta em sua entrada a seguinte frase "tesouro dos remédios da alma" 3 . Os gregos utilizaram a leitura de livros como tratamento médico e espiritual e denominaram as bibliotecas como "a medicina da alma".

Com a utilização da leitura como processo biblioterapêutico, é possível que as pessoas enfermas (devido a problemas mentais e/ou físicos) consigam extrair dos momentos de leitura dirigida maneiras de resolverem seus problemas e de melhorarem sua condição de vida com histórias cativantes e de superação.

Os leitores inseridos na terapia buscariam, por assim dizer, identificação com personagens e com as histórias lidas, suas características e semelhanças, podendo então extrair formas para a resolução de problemas internos e externos que afetam a rotina do dia a dia. Dessa forma, o resultado desse processo biblioterapêutico tende a ser positivo e recompensador para o leitor.

i De acordo com a Wikipédia, "Em arquitetura, frontispício é um elemento arquitetônico constituído, genericamente, pelos elementos decoradores da parte frontal de uma construção, sobretudo na área da fachada. Sua composição reflete o período histórico da obra arquitetônica, sendo característico de uma escola." 
Com a biblioterapia, o leitor realiza um diálogo com o autor da história e mergulha em um universo com possibilidades que permitem uma mudança de espírito. "O autor e o leitor participam, portanto de um jogo de fantasia; jogo que sequer se iniciaria se o texto pretendesse ser algo mais do que uma regra de jogo". Dessa forma, a leitura se torna prazerosa e permite ao leitor um tratamento terapêutico da situação em que se encontra.

\section{Biblioterapia nos Estados Unidos}

As bibliotecas de hospitais, incluindo aquelas desenvolvidas para uso de pacientes, dividem uma história com os próprios hospitais na evolução dos serviços de saúdeii. É bem documentada a origem da biblioteca como um componente dos antigos 'abrigos para insanos'nos Estados Unidos, e muitas foram estabelecidas em meados do século XIX ${ }^{10}$.

Essas bibliotecas existiam como forma de recreação para os pacientes daqueles abrigos ${ }^{10}$.

Antes do século XIX, o dilema dos mentalmente insanos era visto em sua maior parte como uma superstição. Acreditava-se que os enfermos haviam sido possuídos por Satã ou se encontravam sob punição de Deus por seus pecados, e eram escondidos pela família ou confinados em asilos públicos ou em cadeiasiii. No início daquele século, um movimento religioso conhecido como 'O Segundo Grande Despertar' varreu o país e conduziu uma série de reformas sociais, como direitos das mulheres, abolição e uma melhor compreensão das doenças mentais ${ }^{i v}$. Pela primeira vez, a insanidade foi encarada como um problema de natureza fisiológica e poderia ser tratada e, muitas vezes, curadav. O abrigo psiquiátrico era idealizado como um local calmo e seguro, onde os pacientes portadores de doenças mentais poderiam repousar e se recuperar. Uma parcela significativa dessa recuperação adicionava ao tratamento clínico uma 'terapia moral', que promovia atividades como jardinagem, carpintaria, jogos, costura e leitura. Foi nesse movimento da terapia moral que a biblioterapia foi concebida, caracterizando-se pela utilização de livros e da leitura como forma de cura para doenças físicas e mentais ${ }^{\text {vi }}{ }^{10}$. [...]

Enquanto muitos médicos que participavam do movimento de terapia moral geralmente eram favoráveis à prática da biblioterapia, aquilo que os pacientes deveriam ler era muito discutido. Rush defendia que os pacientes deveriam ser introduzidos à ficção ${ }^{\text {vii }}$, afirmando que a leitura de romances funcionaria como uma diversão necessária àqueles que padeciam com doenças mentais. No entanto, nem todos concordavam ${ }^{10}$. [...]

No final do século XIX, o censo de pacientes apontava que a maioria dos abrigos dos Estados Unidos tinha rapidamente começado a perder sua capacidade de abrigar em suas dependências todos os pacientes. Um dos motivos para isso foi a explosão demográfica devido à imigração. A superlotação hospitalar rapidamente acabou com a calma e o tempo intensivo da terapia moral. Assim, muitos abrigos, para grande frustração de lideranças institucionais, passaram a ter uma função mais de custodiar do

ii Wolfgram PA. Hospital libraries in the United States: historical antecedents. Bull Med Libr Assoc. 1985 Jan; 73(1):32-8 apud ${ }^{10}$.

iii Dadoly JL, Levin L, Palmer LA. Dr. Samuel B. Woodward: a 19th century pioneer in American psychiatric care. Poster presented at: MLA '05, 105th Annual Meeting of the Medical Library Association; San Antonio, TX; 14-19 May 2005 [cited 23 Jul 2012] apud $^{10}$.

iv Tomes N. The art of asylum-keeping: Thomas Story Kirkbride and the origins of American psychiatry. Philadelphia, PA: University of Pennsylvania Press; 1994 apud $^{10}$.

v Grob GN. The state and the mentally ill: a history of Worcester State Hospital in Massachusetts, 1830-1920. Chapel Hill, NC: University of North Carolina Press; 1966 apud $^{10}$.

vi Brewster E. 'Medicine for the soul': bibliotherapy and the public library [thesis] [Internet] [Sheffield, UK]; University of Sheffield; 2007. p. 75. [cited 23 Jul 2012] apud ${ }^{10}$.

vii Rush B. Medical inquiries and observations upon the diseases of the mind [facsim. of the Philadelphia, 1812 ed.] New York, NY: Hafner; 1962 apud $^{10}$. 
que terapêuticaviii. Entre as atividades que foram afetadas por essas mudanças estava a de programas de leitura para os pacientes ${ }^{10}$.

Isto contudo não representou o fim da biblioterapia. O movimento simplesmente migrou das terapias morais, geralmente supervisionadas por um superintendente dos abrigos (ou mesmo por um paciente) para um serviço especial aos cuidados de funcionários treinados para essa finalidade. Em 1904, E. Kathleen Jones, bibliotecária-chefe do Hospital McLean em Belmont, Massachussetts, se tornou a primeira profissional a praticar a biblioterapia com pacientes como parte de suas tarefas oficiais ${ }^{i x}$. Hoje, a biblioterapia é comumente usada no âmbito da terapia cognitiva comportamental. Os bibliotecários não se proliferaram como os médicos na bibiografia, muito provavelmente devido ao treinamento específico e certificações exigidas para o trabalho junto a pacientes em um ambiente clínico”x,10.

O que não significa dizer que a biblioterapia não foi uma parte essencial do tratamento daqueles enfermos. Embora esse método tenha evoluído juntamente ao tratamento de doenças e males da mente, suas raízes e conexões com a biblioteca e a biblioteconomia ainda se encontram intactas

\section{Biblioterapia no Brasil}

No Brasil, o tema ainda é pouco explorado, o que contribui diretamente para a dificuldade em se determinar o início da prática. Já na década de 1930, técnicas referentes à biblioterapia eram empregadas em hospitais psiquiátricos e instituições similares com resultados satisfatórios ${ }^{11}$. Alguns autores destacam a aplicação dessas práticas em hospitais de São Paulo, no Instituto dos Cegos de João Pessoa e também da Paraíba, entre outros. A biblioterapia configurava-se então como a implementação de uma série de atividades que envolviam leituras individuais e/ou em grupo, encenações com fantoches, teatro e outras experiências lúdicas.

Existem apenas algumas iniciativas pontuais, tais como pesquisas isoladas e alguns grupos de contadores de histórias que se encaixam no perfil proposto. Ribeiro ${ }^{12}$ afirma que, de acordo com Almada ${ }^{x i}$, a prática da biblioterapia no Brasil teve início na década de 1970, por meio de projetos de extensão, entre os quais se destacaram: o "Carro-Biblioteca" e o das "Caixas estantes", ambos da Universidade Federal do Rio Grande do Sul (UFRGS); o projeto de leitura de contos em hospitais, asilos, creches e escolas intitulado "Hora do Conto"; e "O Livro de Cabeceira".

Ainda segundo Ribeiro ${ }^{12}$, na década de 1990, houve a criação da "Casa da Leitura", pela Universidade Federal do Rio de Janeiro (UFRJ), em parceria com a Fundação Biblioteca Nacional (FBN). A autora se refere também ao início, em 2000, do projeto "Biblioteca Viva em Hospitais", apoiado pelo Ministério da Saúde (MS) e a outras experiências de implantação da biblioterapia com crianças em hospitais universitários: Universidade Federal de Santa Catarina (UFSC); Hospital Universitário Infantil Albert Sabin (HIAS), no Ceará, e o Núcleo de Apoio à Criança com Câncer (NAAC), na Paraíba ${ }^{12}$.

\footnotetext{
viii Grob GN. The state and the mentally ill: a history of Worcester State Hospital in Massachusetts, 1830-1920. Chapel Hill, NC: University of North Carolina Press; 1966 apud $^{10}$.

ix Rubin RJ. Using bibliotherapy: a guide to theory and practice.Phoenix, AZ: Oryx Press; 1978. p. 12 apud ${ }^{10}$.

$x$ Pehrsson DE, McMillen P. Competent bibliotherapy: preparing counselors to use literature with culturally diverse clients [Internet]Corvallis, OR: Oregon State University; 2006. [cited 31 Jul 2012]. <https://www.counseling.org/resources/library/vistas/ vistas06_online-only/Pehrsson.pdf> apud ${ }^{10}$.
}

xi Almada, M. Social: compromisso do ser bibliotecário. In: Jornada Norte-Nordeste de Biblioteconomia e Documentação, 4., 2003, Recife apud ${ }^{12}$. 


\section{Conceitos de biblioterapia}

A palavra biblioterapia deriva do grego biblíon, que significa livro e therapeia, que significa tratamento. Como muitos autores afirmam, trata-se de um processo terapêutico por meio da leitura, que propicia um alívio ao sofrimento das pessoas. Ouaknin considera que "A biblioterapia é o uso dos materiais de leitura selecionados como auxiliares terapêuticos em medicina e psiquiatria. É também o auxílio na solução de problemas por meio de leitura dirigida" ${ }^{13}$.

Para Shrodes, a "biblioterapia é um processo dinâmico de interação entre a personalidade do leitor e a literatura imaginativa, que pode atrair as emoções do leitor e liberá-las para o uso consciente e produtivo"14. Assim, é possível que o próprio leitor se identifique com os personagens da história lida e possa adquirir um estímulo para solucionar seus problemas pessoais.

Segundo Ferreira, a "biblioterapia é vista como um processo interativo, resultando em uma integração bem sucedida de valores e ações"8. E, no dicionário Dorland's Illustrated Medicinal Dictionary, em 1941, a biblioterapia foi definida como "emprego de livros e de sua leitura no tratamento de doenças mentais"

A biblioterapia possui vários conceitos e, até o momento, não se tem um em definitivo. Percebe-se que esse processo de terapia pode ser aplicado a qualquer pessoa que esteja passando por dificuldades. Pode ser trabalhado com crianças, adolescentes, adultos e idosos que vivenciem diferentes contextos.

Com a apresentação e inclusão da biblioterapia no tratamento de pessoas de diversas idades inseridas em diversos cenários, é possível encontrar elementos como, a catarse, o humor, a identificação, a introjeção, a projeção e a introspeção.

A "catarse é definida como purgação, purificação". O filósofo grego Aristóteles acreditava que, através da catarse, era possível eliminar do corpo os males e estabelecer o equilíbrio da saúde. O que se pode dizer é que a catarse é a liberdade emocional; dela é possível retirar a carga negativa acumulada no corpo.

O humor é outro elemento que pode ser aplicado à biblioterapia. Caldin ${ }^{16}$ salienta que Freud "observa que o humor se configura como um triunfo do narcisismo, visto que o ego se recusa a sofrer". O humor é essencial para se buscar um resultado positivo na biblioterapia, pois conforme dito, ele é responsável por desenvolver no ser humano uma sensação de bem-estar. É possível que os sentimentos ruins fiquem em segundo plano ou até mesmo esquecidos.

$\mathrm{Na}$ identificação, o indivíduo pode retirar das experiências de leitura, personagens que se encontram em situações semelhantes às que estão presentes em sua vida. A identificação é utilizada no processo de biblioterapia, pois o leitor/paciente pode se identificar com algum personagem da história lida. Dessa forma, extrai do personagem ação e emoções por ele vivida.

A introjeção "constitui-se em um processo evidenciado pela investigação analítica" 7 . Sendo assim, conforme indica Caldin7, segundo Laplanche e Pontalis, "o sujeito faz passar, de um modo fantasístico, de 'fora' para 'dentro', objetos e qualidades inerentes a esses objetos”. A introjeção está relacionada à identificação.

Ainda de acordo com Caldin", para Laplanche e Pontalis, "a projeção é uma operação pela qual o sujeito expulsa de si e localiza no outro - pessoa ou coisa - qualidades, sentimentos, desejos e mesmo objetos que ele desconhece ou recusa nele". Assim, "a projeção é a transferência aos outros de nossas ideias, sentimentos, intenções, expectativas e desejos"?.

A introspecção se dá no momento em que os leitores se identificam com os personagens, ou seja, têm o conhecimento de que aquele personagem possui características semelhantes, atributos, defeitos e qualidades. "Dá-se a introspecção, o que, para alguns é uma percepção interna, e para outros, um ato deliberado da consciência"”.

A biblioterapia pode ser apresentada em três formas: institucional, clínica e de desenvolvimento pessoal. A "biblioterapia institucional é a que se refere ao uso de literatura - primeiramente didática - com 
clientes, individualmente, e que já se encontra institucionalizada" ${ }^{15}$. Esse tipo de biblioterapia utiliza textos de higiene mental e são recomendados a pacientes mentais. Conta com a participação de bibliotecários e médicos ou de uma equipe médica.

A clínica é realizada por meio de programas estruturados com a participação de psicoterapeutas, médicos e bibliotecários. Tem por objetivo a mudança de atitude por parte dos pacientes e uma solução ou melhora da situação/problema por eles vivenciado. A biblioterapia clínica visa auxíliar um grupo selecionado para o tratamento ou um indivíduo em determinada clínica ou hospital. Possui um enfoque voltado para pessoas com problemas de saúde mental e distúrbio comportamental.

No que se refere ao desenvolvimento pessoal, a biblioterapia é indicada para programas educacionais voltados para crianças e adolescentes, podendo ser trabalhada de forma coletiva e possui um caráter preventivo e corretivo. A "biblioterapia para o desenvolvimento pessoal é descrita como apoio literário personalizado para possibilitar um desenvolvimento normal e progressivo da pessoa que procurou ajuda" .

\section{A biblioterapia realizada no Brasil e no exterior}

Neste tópico, apresentamos os resultados da pesquisa bibliográfica tanto das iniciativas realizadas no Brasil quanto no exterior.

\section{Iniciativas brasileiras}

No Brasil, em diversos ambientes, como as universidades e Ongs, estudantes, professores e profissionais da psicologia e biblioteconomia desenvolveram projetos de biblioterapia. As regiões em que mais iniciativas foram encontradas são a Região Sul, Nordeste e Sudeste. Não foram descobertas experiências nas regiões Norte e Centro-Oeste no período compreendido pela pesquisa.

Em A aplicação da biblioterapia em crianças enfermas ${ }^{17}$, Bueno e Caldin analisam uma experiência com a arte de contar histórias, a leitura e a dramatização como forma de terapia para as crianças internadas na ala pediátrica do Hospital Universitário de Florianópolis - SC. As autoras utilizaram métodos que envolveram principalmente a visão e a audição para criar um espaço imaginário, explorando a criatividade e a imaginação, mas preservando o teor infantil. Foram observadas mudanças culturais nas crianças, como o maior hábito para a leitura, pois as mesmas passaram a procurar na sala de recreação, além dos brinquedos, os livros infantis ${ }^{17}$.

No que diz respeito a $\mathrm{O}$ papel da contação de histórias com biblioterapia: a experiência do projeto histórias na creche do núcleo da hora do conto - Fabico/UFRGS na creche da Instituição Amigo Germano ${ }^{18}$, Teixeira discorre sobre a contação de histórias como forma de biblioterapia. Esta foi aplicada em crianças matriculadas na Creche da Instituição Amigo Germano, em Porto Alegre. O projeto, intitulado Histórias na Creche, tinha por objetivo resgatar a afetividade perdida e buscar o reequilíbrio emocional das crianças, por meio da contação de histórias. Com esse projeto, os funcionários da creche (psicólogos, diretores e professoras) perceberam melhora no comportamento das crianças, pois conseguiram trabalhar conflitos internos e aumentar a autoestima. A análise de dados foi realizada com base nas entrevistas com crianças e funcionários da creche.

Já em Biblioterapia: atividades de leitura desenvolvidas por acadêmicos do curso de biblioteconomia da Universidade Federal de Santa Catarina ${ }^{16}$, Caldin utilizou a disciplina optativa de biblioterapia do curso de Biblioteconomia da Universidade Federal de Santa Catarina para propor aos seus alunos projetos a serem aplicados. Ao todo, foram realizados oito projetos, sendo que cinco foram realizados com crianças, um com jovens e adultos e dois com idosos. Todos esses projetos, que tiveram como objetivos a inserção da leitura e de atividades diversas, como teatro, contação de histórias, filmes e músicas como forma de terapia, alcançaram resultados satisfatórios. 
No estudo Biblioterapia: uma experiência com pacientes internados em clínicas médicas ${ }^{19}$, Seitz implantou um projeto de biblioterapia no tratamento dos pacientes internados no Hospital Universitário da Universidade Federal de Santa Catarina (HU/UFSC). O projeto teve como objetivo investigar a aceitação da biblioterapia como forma de lazer pelos pacientes internados no hospital. A "prática biblioterapêutica com pacientes internados em Clínicas Médicas demonstrou ser útil no processo de hospitalização, tornando a hospitalização menos agressiva e dolorosa"19.

Aplicação da biblioterapia em idosos da Sociedade Espírita Obreiros da Vida Eterna (SEOVE) ${ }^{20}$, consiste no relatório das atividades de biblioterapia que Rossi, Rossi e Souza desenvolveram naquela instituição, localizada em Florianópolis/SC. O objetivo que tinham com essa aplicação era proporcionar o alívio de tensões, aumentar a autoestima, sociabilização e diminuir o estresse das idosas ali internadas. Além de leitura, foram utilizados encenação de bonecos de mão, vídeo de sapateado, músicas de marchinha, diálogos sobre diversos assuntos relacionados com o dia a dia. Com esse projeto, as autoras perceberam a grande importância da biblioterapia para a sociedade, uma vez que ele propiciou às internas da Sociedade Espírita uma renovação de humor, um momento de descontração que permitiu a sociabilização, o diálogo e a alegria dos sujeitos-alvo dessa iniciativa. Em suma, as atividades biblioterapêuticas contribuíram para a mudança de humor daquelas idosas.

Em O uso da biblioterapia em sala de aula ${ }^{21}$, Goularte narra um projeto de biblioterapia que ela realizou com crianças da $1^{\mathrm{a}}$ série da Escola de Educação Básica Professor Benonivio João Martins, localizada no Município de Palhoça-SC. Esse projeto teve por intuito promover a catarse com a contação e narração de histórias. A estudante desenvolveu, além da narração e contação de histórias, a leitura e atividades diversas, para conseguir a participação de todos os alunos. Assim, como retorno do projeto, as crianças se tornaram livres, com espírito de equipe, contribuindo para melhorar a criatividade e a participação em sala de aula.

O texto Biblioterapia: um estudo de caso da prática de leitura realizada com pessoas com necessidades psicossociais ${ }^{22}$ mostra como Lopes realizou um estudo com vários pacientes (mulheres e homens) do Centro de Apoio Psicossocial do Hospital de Clínicas de Porto Alegre/RS. A autora utilizou a leitura de revistas, jornais e livros como instrumentos para aplicação do projeto e realizou uma pesquisa qualitativa para garantir um resultado mais completo do tratamento. O projeto foi desenvolvido na biblioteca do hospital em quatro encontros e com o auxílio de uma enfermeira, uma estagiária de enfermagem e uma professora. De acordo com a autora, a biblioterapia contribuiu para melhorar o convívio social, o desenvolvimento da oralidade e do raciocínio, além de desenvolver o processo cognitivo a partir das atividades de leitura por esses pacientes.

Em As cartas de Ana Cristina César: uma contribuição para a biblioterapia ${ }^{23}$, Rosa realizou uma pesquisa de campo com homens e mulheres, e utilizou como processo terapêutico cartas de Ana Cristina Cruz Césariii dirigidas as três de suas amigas e dispostas no livro Correspondência incompleta. A escolha do material baseou-se nas situações do cotidiano, problemas afetivos e crises existenciais, que são comuns a muitas pessoas. Com as cartas de Ana Cristina César, tornou-se possível aos leitores se identificarem com situações do cotidiano e com a intimidade da autora. Com uma linguagem que se aproxima do real, as cartas provocaram nos leitores uma reflexão sobre as situações escritas. De acordo com Rosa, as leituras das cartas permitiram aos participantes o incentivo à apreciação de si, incentivaram a busca de novos interesses, liberaram a pressão emocional e/ou mental, e estimularam a discussão aberta dos problemas e de maneiras possíveis de solucioná-los.

xii Ana Cristina César foi uma poetisa. Escreveu inúmeras poesias e cartas, além de escrever para diversos jornais e revistas Ana Cristina faleceu em 1983. Ela deixou uma série de documentos, tais como cartas, poesia, diários, traduções, desenhos e testemunhos. 
Em Biblioterapia para alunos com necessidades educacionais especiais na APAE de Capitólio-MG: aplicabilidade e resultados ${ }^{24}$, Arantes realizou o projeto através de contação de histórias, xilogravuras, desenhos, colagens e pinturas em cartolina, e leitura de histórias. A aplicação contou com a participação de crianças da faixa etária de três a quinze anos. Conforme a autora, foi possível perceber que, com a biblioterapia, os participantes tiveram uma mudança positiva do comportamento e despertaram emoções como alegria, amizade, apoio, companheirismo, compreensão, entre outros.

Em Manhã de leitura afetuosa: um programa biblioterápico com crianças com perfil do transtorno do déficit de atenção e hiperatividade (TDAH) ${ }^{\text {xii }}$ em Escola Municipal de Formiga - MG ${ }^{25}$, Fonseca, Rodrigues e Borges realizaram um projeto de biblioterapia com 14 crianças com TDAH, de faixa etária de oito a doze anos, da terceira a quinta série. Para isso, utilizaram a contação de histórias e atividades lúdicas, como oficina de criatividade, passeio e brincadeira, como método de terapia. O projeto melhorou o gosto pela leitura, motivação, comunicação e autoestima.

Em A biblioterapia no tratamento do câncer infantil ${ }^{26}$, Fontenele e colaboradores aplicaram a biblioterapia em crianças internadas na ala de oncologia do HIAS (Hospital Infantil Albert Sabin). Essa experiência durou cinco anos. Nela, foram utilizados histórias e contos de fadas como Pinóquio, A bela adormecida e Os três porquinhos, entre outros. Esse procedimento foi realizado juntamente com a área de psicologia do hospital. Com esse projeto, foi possível incentivar a leitura. A "partir de nossa experiência, verificamos que a leitura, associada a outros recursos lúdicos, é um instrumento eficaz na conquista da melhoria da qualidade de vida das crianças portadoras de câncer”26.

Contar histórias para crianças hospitalizadas: relato de uma estratégia de humanização ${ }^{27}$ relata e analisa um projeto de contação de histórias com diversas pessoas que se encontravam no Hospital Infantil Albert Sabin - CE. Contou com a participação de doze pessoas, entre elas, três crianças, três acompanhantes, três mediadores (terapeuta ocupacional, bibliotecária e voluntária) e três outros profissionais. Como resultado desse projeto, de acordo com os participantes, houve alívio da dor e/ou esquecimento momentâneo da doença, sentimentos de alegria, relaxamento e confiança. Contribuiu também para a melhora da autoestima, imaginação, melhora e desenvolvimento da leitura.

Em Biblioterapia para idosos: o que fica e o que significa ${ }^{28}$, Castro e Pinheiro narram e analisam a biblioterapia que proporcionaram aos idosos da Associação Metropolitana de Erradicação da Mendicância (Amem). As autoras realizaram atividades lúdicas de leitura (contos clássicos, literatura infanto-juvenil, revistas semanais e alguns materiais escolhidos pelos participantes) e utilizaram a entrevista para conhecer o perfil dos idosos e sua história. A partir desse projeto, buscaram argumentos para validar a biblioterapia como uma prática capaz de fazer com que os idosos esquecessem suas limitações e proporcionar um envelhecimento mais feliz aos mesmos.

Em Aleitura éo melhor remédio: a biblioterapia com crianças portadora de câncer ${ }^{29}$, Elliot e colaboradores revelam um projeto de biblioterapia que desenvolveram com crianças portadoras de câncer internadas no Hospital Municipal Infantil Maria Amélia Bezerra de Menezes, localizado na Cidade de Juazeiro do Norte, CE. Esse projeto teve como característica as técnicas de leitura e de desenho. Os participantes visitaram o hospital duas vezes por semana, para a realização e reunião referente às ações do projeto. Como leitura, foram utilizados contos como o O caso do bolinho, de Tatiana Belinky, que além da leitura o leitor pode contemplar as ilustrações. Com esse projeto, foi possível analisar os traços psicológicos das crianças e promover um tratamento que propiciasse a pacificação das emoções e aceitação da condição em que se encontram, e ainda o gosto pela leitura.

xiii O TDAH implica em uma desordem de comportamentos diferenciados da vida social, emocional, escolar e familiar do portador. 
Todas as experiências relatadas demonstram a importância da aplicação da biblioterapia em todos aqueles que estejam passando por situações conflitantes, como colocadas anteriormente. Conforme analisado, esses projetos contribuíram para melhorar a situação dessas pessoas, além de incentivar a leitura.

Os bibliotecários e psicólogos que realizaram essa terapia disponibilizaram as técnicas e coleta de dados realizada como forma de transmitir interesse e divulgar as práticas e resultados obtidos para outros profissionais.

\section{A biblioterapia norte-americana}

Neste tópico apresentamos as iniciativas norte-americanas de aplicação da biblioterapia. Foram encontrados sete trabalhos, compreendendo teses, dissertações e artigos científicos. Não foi possível identificar a região das iniciativas aqui relatadas.

Em Using bibliotherapy with gifted children ${ }^{30}$, Frasier e McCannon montaram um guia para auxiliar professores e bibliotecários na produção de projetos de biblioterapia a serem realizados com alunos superdotados, uma vez que eles são considerados problemáticos, pois, segundo elas, essa condição interfere no desenvolvimento social e educacional. Esse guia divide os problemas enfrentados por tais alunos em: (a) tédio devido ao currículo escolar desestimulante; (b) problemas sociais e/ou comportamentais; e (c) problemas de desenvolvimento. E, como forma de terapia, estabelece a utilização do livro. Ainda de acordo com as autoras desse guia, o professor deve ler todos os livros do projeto, que devem estar disponíveis em sala de aula, e o tempo deve ser suficiente para que os alunos leiam as obras.

The outcome of cognitive bibliotherapy with depressed adults ${ }^{31}$ resulta de um estudo realizado por Jamison e Scogin com pessoas que sofrem de depressão. Dele participaram cerca de 80 pessoas com idade média de 40 anos. A terapia foi realizada a partir de livros de autoajuda que abordavam o problema da depressão. Os livros abordados instruíam o leitor a identificar problemas, interpretá-los e, assim, solucioná-los. Após a leitura de cada livro, a biblioterapeuta realizava entrevistas para analisar as emoções dos participantes. Com a biblioterapia, os participantes apresentaram diminuições significativas nos níveis de depressão. Assim, o tratamento foi eficaz e contribuiu para a redução dos sintomas.

Já Bibliotherapy ${ }^{32}$ é um artigo que aborda a biblioterapia para o desenvolvimento pessoal de crianças do ensino básico . Com a biblioterapia, as crianças podem se identificar com os personagens da literatura e de desenhos animados. Cook, Earles-Vollrath e Ganz salientam a importância do papel do bibliotecário na apresentação da biblioterapia juntamente com o professor e diretor do estabelecimento escolar. As autoras apresentam etapas fundamentais para aplicar a biblioterapia: identificar o problema, situação, comportamento ou habilidade a ser adquirida; seleção de literatura adequada ao perfil dos participantes; apresentação da literatura e acompanhamento da leitura; e discussão do que foi abordado. A biblioterapia é uma ferramenta que os professores, bibliotecários e conselheiros escolares podem usar para atender às necessidades consideráveis de alunos com e sem deficiência, particularmente aqueles com dificuldade de aprendizagem e problemas de comportamento assim como os de diferentes culturas e de diversas origens linguísticas ${ }^{32}$.

O projeto de pesquisa de Harper que fundamenta a sua tese de doutorado Bibliotherapy intervention exposure and level of emotional awareness among students with emotional and behavioral disorders ${ }^{33}$ envolveu 182 crianças de seis a treze anos de idade. Esse estudo analisa a aplicação da biblioterapia em crianças com distúrbios emocionais e comportamentais. A autora realizou uma coleta de dados quantitativa e qualitativa e, com a realização de entrevistas, percebeu que, com a leitura de livros, as crianças se identificavam com os personagens. Esse estudo traz contribuições importantes para os interessados em futuras intervenções nessa área e o trabalho de biblioterapia nele analisado se revelou fundamental para as crianças, pois a leitura contribuiu para a compreensão dos problemas e ajudou-as a enfrentar situações rotineiras.

Em A randomized trial of ACT bibliotherapy on the mental health of K-12 teachers and staff ${ }^{34}$, Jeffcoat e Hayes apresentam uma pesquisa realizada com diversas pessoas de 18 anos de idade ou mais, para identificar 
o grau de estresse e depressão e, com base nos resultados, aplicar a biblioterapia como forma de amenizar os problemas emocionais causados pela rotina diária. A pesquisa foi realizada em 236 escolas que tiveram um alto grau de interesse pelo programa voltado para o bem-estar, duas vezes acima do esperado. Os participantes eram, em sua maioria, do sexo feminino, e ocupavam cargos diversos. Entre eles, havia administradores, conselheiros, psicólogos, analistas de comportamento, bibliotecários, curadores, enfermeiros, professores, técnicos e especialistas. O tratamento foi realizado por meio da leitura de um livro. Cada participante teve oito semanas para realizar a leitura e preencher seis questionários referentes ao material lido. Após a leitura, receberam uma avaliação e acompanhamento de 10 semanas para entender a extensão da sua leitura e o uso do livro. Os questionários aplicados tiveram como objetivo avaliar os problemas específicos de cada pesquisado. A aplicação da biblioterapia nesse grupo teve resultados positivos, pois melhorou a saúde mental e permitiu o controle do estresse e depressão das pessoas que dela participaram.

Já em Bibliotherapy for low sexual desire: evidence for effectiveness ${ }^{35}$, Mintz, Balzer, Zhao e Busch apresentam os resultados de um estudo exploratório com 45 mulheres, da faixa etária de 28 a 57 anos, de diferentes naturalidades e religiões, casadas e com pouco desejo sexual . Esse estudo foi realizado em sete semanas e demonstrou que as mulheres que leram o livro proposto tiveram seu desejo sexual aumentado. O livro utilizado para o estudo é voltado especificamente para mulheres com esse problema. O tema do estudo teve resultados positivos, uma vez que as mulheres refletiram sobre o próprio desejo sexual e isso proporcionou-lhes benefícios não só do ponto de vista do desejo, mas também de todo o funcionamento sexual.

Esses artigos refletem algumas experiências norte-americanas que utilizam a biblioterapia . Eles demonstram como a prática biblioterapêutica possui resultados positivos e como a leitura é fundamental para atingi-los.

\section{Prática da biblioterapia brasileira e norte-americana: análise comparativa}

Ao observar os projetos de biblioterapia, é possível perceber os benefícios por ela propiciados, como controle das emoções, alegria e a melhora de comportamento, entre outros.

Os biblioterapeutas brasileiros aqui apresentados utilizaram, juntamente com a leitura, atividades lúdicas, como contação de histórias, projeção de filme, desenho, encenação de teatro, dança, um acervo variado para complementar o papel da leitura. Com esse trabalho, os resultados obtidos foram satisfatórios, pois permitiram a abertura de um mundo desconhecido, a leitura, pelos usuários/pacientes que fizeram parte desses projetos.

A biblioterapia norte-americana aqui abordada trabalha com aspectos psiquiátricos e termos ligados à mente humana, buscando formas de tratamentos e resultados específicos. Os grupos em que é aplicada são escolhidos em locais pré-determinados e, de modo geral, constituídos por pacientes/usuários com perfis relacionados a casos problemáticos.

Na prática norte-americana o material de leitura, utilizado nos projetos, se baseia apenas no livro e busca histórias específicas que se assemelhem ao problema em questão. Diferentemente da aplicação brasileira, os norte-americanos realizam o tratamento durante um longo período e aplicam questionários durante esse tempo. Percebe-se que alguns biblioterapeutas norte-americanos realizam guias de como aplicar a biblioterapia em grupos específicos.

Biblioterapeutas do Brasil e dos Estados Unidos utilizam o livro para o desenvolvimento da terapia e o acompanhamento realizado com os pacientes/leitores ocorre no mínimo até o término da leitura. Para desenvolver os projetos de aplicação da biblioterapia, profissionais dos dois países utilizam a revisão de literatura referente ao tema.

Os brasileiros utilizam o livro e outras atividades para a complementação do tratamento, buscando atingir todos os públicos. Há também muitos bibliotecários nas participações da terapia. Nos projetos 
consultados, os norte-americanos utilizam somente o livro, questionários e entrevistas para a aplicação da biblioterapia e buscam públicos definidos, com problemas mais profundos e específicos. Nota-se a presença de psiquiatras e psicólogos na aplicação dos projetos e poucos mencionaram bibliotecários.

Por meio da leitura dos projetos brasileiros e norte-americanos foi possível apresentar suas principais diferenças. No entanto, não cabe aqui afirmar se a prática brasileira é melhor que a norte-americana ou viceversa, pois cada uma possui sua particularidade. É claro que é possível inserir novas ideias na biblioterapia, pois, assim, ela terá resultados cada vez mais positivos. Para isso, sugere-se, aos norte-americanos, utilizarem a criatividade brasileira e introduzirem mais atividades lúdicas. Os brasileiros poderiam se especializar na prática biblioterapêutica e, semelhantemente aos norte-americanos, buscar contatos com os pacientes/ leitores de outras formas, além da presencial para tomar conhecimento de situações do seu dia a dia.

\section{Conclusão}

Com base no estudo que fundamenta este artigo, percebe-se que a biblioterapia é um assunto de grande importância para a sociedade, pois esta encontra-se sempre em mudança e é afetada por fatores como trabalho, estresse, doenças físicas e psicológicas. Por meio dessa forma de terapia, é possível controlar as emoções.

Os textos aqui apresentados demonstraram as diversas aplicações da biblioterapia e seus diversos públicos-alvo. Nas que foram feitas no Brasil é possível observar bibliotecários e psicólogos em diversas regiões do país com seus programas e resultados satisfatórios. Nas intervenções norte-americanas, vê-se que, por meio de projetos de leitura desenvolvidos por psicólogos e psiquiatras, os resultados também foram positivos.

A biblioterapia não traz a cura e sim um caminho para a resolução de problemas que afligem as pessoas. Percebe-se que a leitura terapêutica na vida das pessoas garante um resultado positivo, pois contribui para uma melhor qualidade de vida, permitindo a melhora do processo emocional ao criar estratégias para resolver situações rotineiras que interferem nos seus estados psicológicos. Por fim, a comparação entre a biblioterapia brasileira e a norte-americana demonstrou que, apesar de algumas diferenças, essa prática produz resultados positivos.

Considerando tais resultados positivos, seria importante que estudos como esses pudessem ser aprofundados no âmbito nacional. Nesse caso, é preciso que um corpo multidisciplinar possa, em conjunto, analisar e estudar as práticas biblioterapêuticas a fim de torná-las mais usuais. A partir daí criar disciplinas, treinamentos e até mesmo cursos de pós-graduação ou de aperfeiçoamento para formar profissionais aptos a trabalhar com esse tipo de terapia.

\section{Referências}

1. Pereira A, Freitas C, Mendonça C, Souza J, Noronha JP, Lessa L, et al. Envelhecimento, estresse e sociedade: uma visão psiconeuroendocrinológica. Ci e Cogn [Internet]. 2004 [citado 2016 nov 08];1(1):34-53. Disponível em: http://www.cienciasecognicao.org/pdf/v01/cec vol 1 m1147.pdf.

2. Martins RM, Hagen SI. Ame suas rugas: aproveite o momento. Santa Catarina: Odorizzi; 2007.

3. Alves MHH. A aplicação da biblioterapia no processo de reintegração social. Rev Bras Bibliotecon Doc. 1982 jan./jul. 15(1/2):54-61.

4. Bueno SB, Caldin CF. A aplicação da biblioterapia em crianças enfermas. R ACB: Bibliotec em Santa Catarina [Internet]. 2002 [citado 2016 nov. 08];7(1):157-70. Disponível em: http://revista.acbsc.org.br/ index.php/racb/article/view/372/446.

5. Matias-Pereira J. Manual de metodologia da pesquisa científica. São Paulo: Atlas; 2007.

6. $\quad$ Martins MH. O que é leitura. 19 ed. São Paulo: Brasiliense; 2006. 
7. Caldin CF. A leitura como função terapêutica: biblioterapia. R Eletr Bibliotec Ci Inf [Internet]. 2001 [citado 2016 nov. 08];6(12):32-44. Disponível em: http://www.periodicos.ufsc.br/index.php/eb/article/ view/36/5200.

8. Ferreira DT. Biblioterapia: uma prática para o desenvolvimento pessoal. ETD [Internet]. 2003 [citado 2016 nov. 08];4(2):35-47. Disponível em: http://periodicos.sbu.unicamp.br/ojs/index.php/etd/article/ view/620

9. Caldin CF. Leitura e terapia [tese on line]. Florianópolis: Universidade Federal de Santa Catarina; 2009 [citado 2016 nov. 08]. Disponível em: http://www.tede.ufsc.br/teses/PLIT0342-T.pdf.

10. Levin L, Gildea R. Bibliotherapy: tracing the roots of a moral therapy movement in the United States from the early nineteenth century to the present. ] Med Libr Assoc [Internet]. 2013 [cited 2016 Nov 08];101(02):89-91. Disponível em: https://www.ncbi.nlm.nih.gov/pmc/articles/PMC3634391

11. Almeida EM, Gomes NM, Silva DMS, Silva ML. Biblioterapia: o bibliotecário com agente integrador e socializador da informação. Mult. Olhar Ci Inf [Internet]. 2013 [citado 2016 nov. 08];3(2):1-15. Disponível em: http://portaldeperiodicos.eci.ufmg.br/index.php/moci/PMC/article/view/2092/1294.

12. Ribeiro G. Biblioterapia: uma proposta para adolescentes internados em enfermarias de hospitais públicos. RBDCI [Internet]. 2006 jan./jun. [citado 2016 nov. 08];3(2):112-26. Disponível em: http:// periodicos.sbu.unicamp.br/ojs/index.php/rdbci/article/view/2048/2178.

13. Ouaknin MA. Biblioterapia. São Paulo: Loyola; 1996.

14. Shrodes C. Biblioteraphy: a theoretical and clinical-experimental study [dissertation]. Berkel: University of California; 1949.

15. Pereira MMG. Biblioterapia: proposta de um programa de leitura para portadores de deficiência visual em Bibliotecas Públicas. João Pessoa: Editora Universitária; 1996.

16. Caldin CF. Biblioterapia: atividades de leitura desenvolvidas por acadêmicos do curso de biblioteconomia da Universidade Federal de Santa Catarina. Biblios: R Elect Bibliot, Archiv y Museol [Internet]. 2005 [citado 2016 nov. 08];6(22):13-25. Disponível em: http://www.redalyc.org/articulo.oa?id=16102202

17. Bueno SB, Caldin CF. A aplicação da biblioterapia em crianças enfermas. R ACB: Biblio em Santa Catarina [Internet]. 2002 [citado 2016 nov. 08];7(1):157-70. Disponível em: http://revistaacbsc.org.br/index. $\mathrm{php} / \mathrm{racb} / \mathrm{article} / \mathrm{view} / 372 / 446$.

18. Teixeira PRN. O papel da contação de histórias como biblioterapia: a experiência do projeto histórias na creche do núcleo da hora do conto - Fabico/UFRGS na creche da Instituição Amigo Germano (trabalho de conclusão de curso). Porto Alegre: Universidade Federal do Rio Grande do Sul; 2004.

19. Seitz EM. Biblioterapia: uma experiência com pacientes internados em clínicas médicas. R ACB: Biblio em Santa Catarina [Internet]. 2006 [citado 2016 nov. 08];11(1):155-70. Disponível em: https://revista. acbsc.org.br/racb/article/view/452/567.

20. Rossi T, Rossi L, Souza M. Aplicação da biblioterapia em idosos da Sociedade Espírita Obreiros da Vida Eterna (SEOVE). R ACB: Biblio em Santa Catarina [Internet]. 2007 [citado 2016 nov. 08];12(2):322-40. Disponível em: https://revista.acbsc.org.br/racb/article/view/505

21. Goularte LF. O uso da biblioterapia em sala de aula (trabalho de conclusão de curso). Florianópolis: Universidade do Estado de Santa Catarina; 2008.

22. Lopes R. Biblioterapia: um estudo de caso da prática de leitura realizada com pessoas com necessidades psicossociais (trabalho de conclusão de curso). Porto Alegre: Universidade Federal do Rio Grande do Sul; 2012.

23. Rosa ALR. As cartas de Ana Cristina César: uma contribuição para a biblioterapia (dissertação). Minas Gerais: Universidade do Vale do Rio Verde; 2006.

24. Arantes DA. Biblioterapia para alunos com necessidades educacionais especiais na APAE de CapitólioMG: aplicabilidade e resultados (trabalho de conclusão de curso). Formiga: Centro Universitário de Formiga; 2008.

25. Fonseca TFG, Rodrigues IF, Borges SCG. Manhã de leitura afetuosa: um programa biblioterápico com crianças com o perfil do transtorno do déficit de atenção e hiperatividade (TDAH) em Escola Municipal de Formiga - MG. Conexão Ci [Internet]. 2012 [citado 2016 nov 09];7(2):74-87. Disponível em: https:// periodicos.uniformg.edu.br:21011/periodicos/index.php/testeconexaociencia/article/view/158 
26. Fontenele MFS, Pinto VB, Andrade FJM, Dias AP, Moura RMG, Pinto JMB. A Biblioterapia no tratamento do câncer infantil [projeto de pesquisa]. Fortaleza: Curso de Biblioteconomia e Psicologia da UFC; 1995.

27. Moreno RLR, Portela DRL, Queiroz ME, Souza SMPO, Silva MSA. Contar histórias para crianças hospitalizadas: relato de uma estratégia de humanização. Pediatria. 2003;25(4):164-69.

28. Castro R, Pinheiro E. Biblioterapia para idosos: o que fica e o que significa. Biblionline [Internet]. 2005 [citado 2016 nov 09];1(2):1-13. Disponível em: http://periodicos.ufpb.br/ojs2/index.php/biblio/article/ view/586/424.

29. Elliot A, Bernardino MC, Rolim Neto ML, Andrade FP, Silva TP. A leitura é o melhor remédio: a biblioterapia com crianças portadora de câncer. In: Anais do 24 Congresso Brasileiro de Biblioteconomia, Documentação e Ciência da Informação; 2011 ago. 07-10; Maceió: FEBAB; 2011.

30. Frasier M, McCannon C. Using bibliotherapy with gifted chidren. Gifted Child Q. 1981;25(2): 81-5.

31. Jamison C, Scogin F. The outcome of cognitive bibliotherapy with depressed adults. J Consult Clin Psycol. 1995;63(4);644-50.

32. Cook K, Earles-Vollrath T, Ganz J. Bibliotherapy. Interv Sch Clin. 2006;42(2):91-100.

33. Harper E. Bibliotherapy intervention exposure and level of emotional awareness among students with emotional and behavioral disorders (tese de doutorado). Cleveland: Cleveland State University; 2010.

34. Jeffcoat T, Hayes S. A randomized trial of ACT bibliotherapy on the mental health of K-12 teachers and staff. Behav Res Ther. 2012;50(1):571-79.

35. Mintz L, Balzer A, Zhao X, Busch H. Bibliotherapy for low sexual desire: evidence for effectiveness. J Couns Psycol. 2012;59(3):471-78. 